\title{
Partial Discharge Behavior under Operational and Anomalous Conditions in HVDC Systems
}

\author{
M. Azizian Fard, M. Emad Farrag, S. G. McMeekin \\ Glasgow Caledonian University \\ Glasgow, UK
}

and A. J. Reid

Cardiff University

Cardiff, UK

\begin{abstract}
Power cables undergo various types of overstressing conditions during their operation that influence the integrity of their insulation systems. This causes accelerated ageing and might lead to their premature failure in severe cases. This paper presents an investigation of the impacts of various dynamic electric fields produced by ripples, polarity reversal and transient switching impulses on partial discharge (PD) activity within solid dielectrics with the aim of considering such phenomena in high voltage direct current (HVDC) cable systems. Appropriate terminal voltages of a generic HVDC converter were reproduced - with different harmonic contaminations - and applied to the test samples. The effects of systematic operational polarity reversal and superimposed switching impulses with the possibility of transient polarity reversal were also studied in this investigation. The experimental results show that the PD is greatly affected by the dynamic changes of electric field represented by polarity reversal, ripples and switching. The findings of this study will assist in understanding the behaviour of PDs under HVDC conditions and would be of interest to asset managers considering the effects of such conditions on the insulation diagnostics.
\end{abstract}

Index Terms - Firing angle, power conversion harmonics, HVDC transmission, insulation, polarity reversal, power system transients, partial discharge, ripples.

\section{INTRODUCTION}

THE introduction of polyethylene in the 1940s initiated a revolutionary progress in the cable industry [1], and since then many polymeric materials have been produced and found applications in cable manufacturing owing to their technical and economical advantages. Accordingly, successful deployment of high voltage direct current (HVDC) projects relying on mass impregnated non-draining (MIND) cables motivated the employment of their polymeric counterparts, particularly, of cross-linked polyethylene (XLPE) material in such applications. The first application of XLPE DC cable was the Gotland project, Sweden, operating at $80 \mathrm{kV}$ in 1998, and since then significant developments have taken place in terms of material, rating and characteristics [2].

The influences of voltage distortion, harmonics and transients on partial discharges $(\mathrm{PD})$ at $\mathrm{AC}$ systems have been investigated in [3-5] and it was reported that these phenomena hasten the insulation degradation. Accordingly, PD diagnostic

Manuscript received on 28 November 2016, in final form 10 February 2017, accepted 13 March 2017. Corresponding author: M.A. Fard. methods have been proposed and developed $[6,7]$. Concerning the principles and the mechanisms of PD under DC fields, remarkable investigations have been carried out $[8$, 9], but the operational nature of HVDC systems introduces some challenges: harmonic injection that appears in the form of ripples in the DC side of the converters influences cable insulation [10]. Some recent studies have focused on PD activity under abnormal conditions that could be imposed by the operational conditions of HVDC equipment, through modelling [11,12] and experimental tests [13, 14]. Moreover, cable insulation is influenced by the normal polarity reversal operation of Line Commuted Converters (LCC); this might be due to accumulation of space charges under the effect of DC electric fields [15-17] that result in locally intensified fields within the cable insulation. This affects the electrical strength of the cable insulation leading to its accelerated aging and premature failure. Transients of internal origins affect the insulation, and could have their origins due to switching operations, converter disturbances or flashover on converter transformer bushings $[18,19]$ or they can emanate as a result of protective operation of circuit breakers, mainly in the $\mathrm{AC}$ side of the HVDC systems [20]. Additionally, a misfiring or 
fire-through of a switching valve, or single/double commutation failure can cause transient overvoltages in the DC side. A single pole to ground short circuit in symmetrical monopole HVDC systems or bipolar schemes might also give rise to induced transient overvoltages [21,22]. The effects of transient overvoltages on cable insulation, particularly $\mathrm{PD}$ behavior, under $\mathrm{AC}$ regime have been studied and the phenomenon is well understood [24-26]. Nevertheless, less research has been devoted to such effects under DC electric fields, especially DC superimposed with transient overvoltages that can also cause transient polarity reversals.

This paper presents the experimental results of investigating the effects of operational and anomalous electric field conditions on PD activity within solid dielectrics. Test voltages involving ripples, polarity reversal, and switching impulses were produced under laboratory conditions and applied to the test sample of polymeric resin with an artificially introduced cavity. The emanant PD pulses were meausred and analysed against the harmonics levels, superimposed switching transient of different polarities with DC voltage, and polarity reversal that will be discussed in their relevant sections.

\section{PARTIAL DISCHARGE MEASUREMENT}

PD measurement is a non-destructive insulation diagnostic method that can be performed online or offline. Generally, the detection method is adopted according to the type of equipment under test. The electromagnetic methods have proved to be more appropriate for the detection of PD pulses in cable system, and they are, generally, categorized as conventional and nonconventional test techniques [6, 7]. In this study, PD pulses originating from an artificially made test sample were detected using an HFCT sensor.

\subsection{PREPARATION OF TEST SAMPLE}

Figure 1 shows the geometry of the test sample. The bulk material of the sample is resin of $3 \mathrm{~mm}$ in thickness including a cavity of $1 \mathrm{~mm}$ in diameter. This resin is a clear type of Poly Urethane (PU). This product is provided in two parts in the market: Formulated Polyo (component A) and Isocyanate (component B). The two components which were kept in a storage temperature between $20-30^{\circ} \mathrm{C}$ were mixed by $1: 1$ weight ratio. The mixture was poured into moulds and after approximately 15 minutes, the time to increase the viscosity of mixture, a controlled amount of air was injected into each sample using a hypodermic needle to produce air bubbles. The

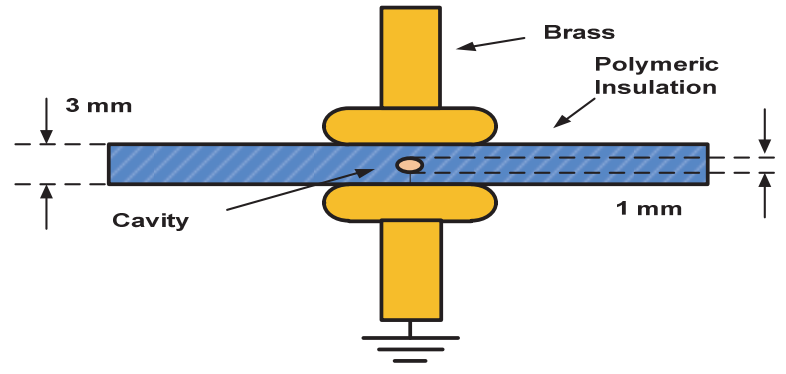

Figure 1. A single gas-filled void test sample. mixture allowed for 24 hours to cure completely. Then the section of the resin containing bubble was separated using a CNC machine and afterwards the bubble size was measured with a microscope. The properties of the test sample and the material are given in Table 1.

Table 1. Test Sample properties.

\begin{tabular}{l|c|c}
\hline \multicolumn{1}{c|}{ Quantity } & VALUE & UNITS \\
\hline $\begin{array}{l}\text { Insulation dimensions (diameter\& } \\
\text { thickness) }\end{array}$ & $85 \times 3$ & $\mathrm{~mm} \times \mathrm{mm}$ \\
$\begin{array}{l}\text { Cavity diameter } \\
\begin{array}{l}\text { Electrode dimensions (diameter\& } \\
\text { thickness) }\end{array}\end{array}$ & 1 & $\mathrm{~mm}$ \\
$\begin{array}{l}\text { Relative permittivity of insulation } \\
\text { Relative permittivity of air }\end{array}$ & $6.30 \times 12$ & $\mathrm{~mm} \times \mathrm{mm}$ \\
Conductivity of insulation & 1 & - \\
\hline
\end{tabular}

\subsection{EXPERIMENTAL SETUP}

The experimental setup for the PD measurement under laboratory conditions is portrayed in Figure 2. Three groups of test voltages have been generated: (1) downscaled terminal voltage of a six-pulse LCC converter and (2) polarity reversal scenarios were produced in an environment of interlinked MATLAB and LabVIEW. This environment for converter voltage is illusterated in Figure 3, in which the MATLAB performs as the processing core to generate the controlled rectified voltages. The characterising parameters and the interfacing with the data acquisition card (DAQ) are performerd through a user interface platform running in LabVIEW. Figure 4 shows a typical generated terminal voltage of a six-pulse HVDC converter. The rectified voltage is a function of firing and commutation angles without consideration of smoothening filter, and (3) the transient switching overvoltages were produced using a programmable function generator (RIGOL DG4000).

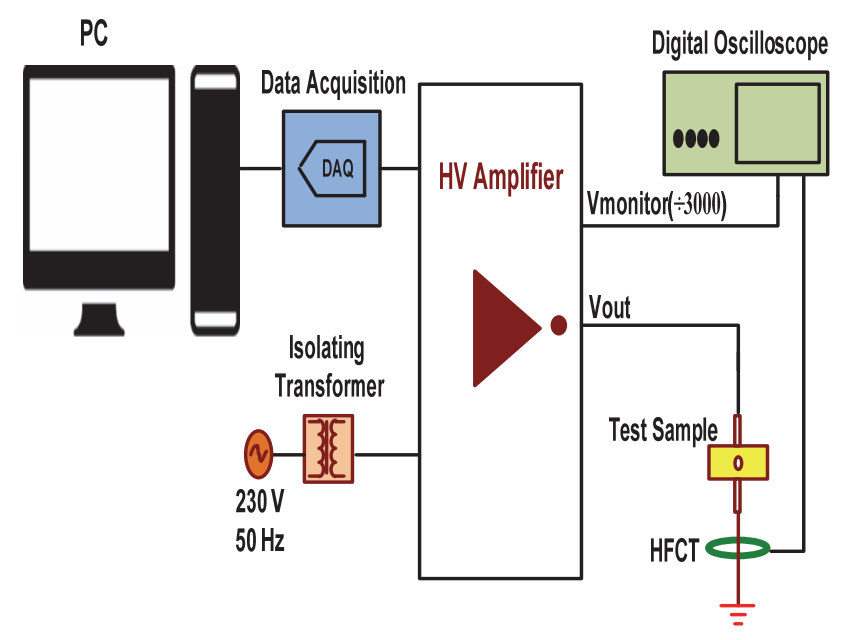

Figure 2. Experimental setup for measuring PD under HVDC electric fields.

The produced converter voltages and polarity reversal were fed into a high voltage (HV) amplifier (Trek model 30/20A) via the data acquisition card (National Instruments) but in the 
case of switching transient the output of the function generator is directly connceted to the HV amplifier. The stable gain of the $\mathrm{HV}$ amplifier is $3 \mathrm{kV} / \mathrm{V}$ with the maximum attainable output of $\pm 30 \mathrm{kV}$. An HFCT sensor was clamped around the ground wire of the test sample to detect PD pulses. This sensor is of HVPD model 100/50AL and has a transimpedance of $4.3 \mathrm{mV} / \mathrm{mA} \pm 5 \%$. The bandwidth of the sensor covers $200 \mathrm{kHz}$ to $19 \mathrm{MHz}$. A digital oscilloscope (LeCroy 7300) with a bandwidth of $3 \mathrm{GHz}$ has been used for the measurement of the detected PD pulses.

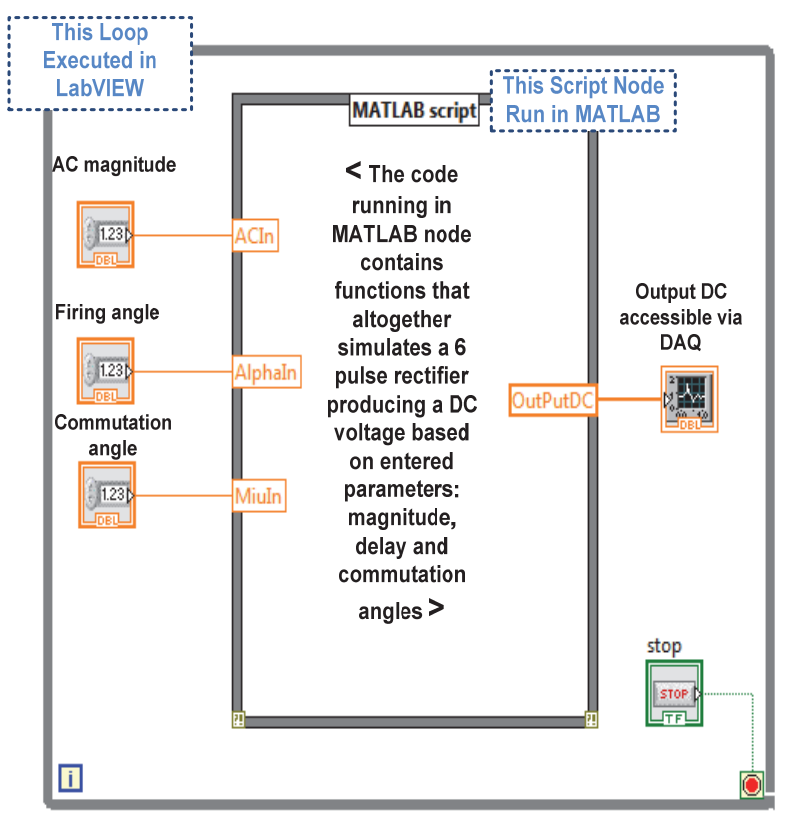

Figure 3. Interlinked MATLAB- LabVIEW platform for generating the test voltages.

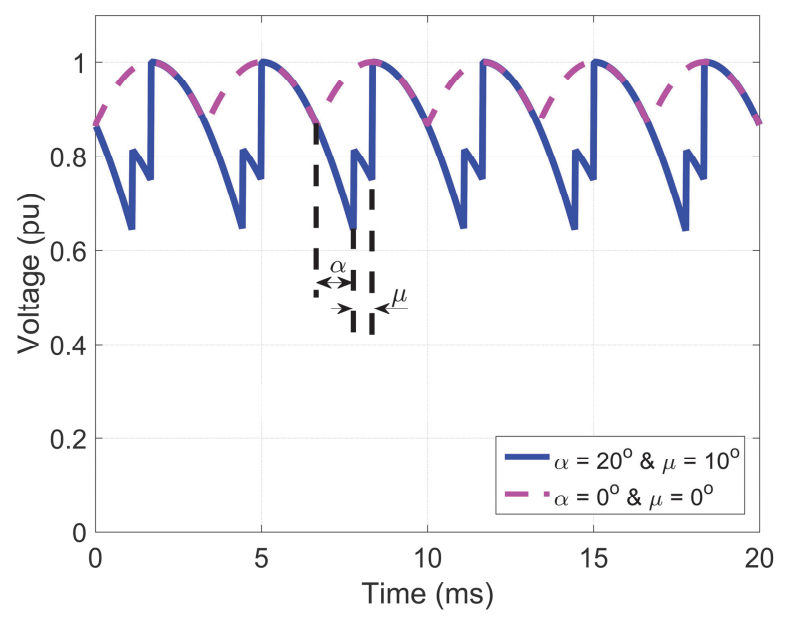

Figure 4. A typical output voltage of a six-pulse LCC converter considering the firing angle $\alpha$ and the commutation angle $\mu$.

\section{EXPERIMENTAL RESULTS}

\subsection{PD BEHAVIOR UNDER VOLTAGE RIPPLES}

The delay angle of thyristors in LCC converters is the governing parameter for the control of direction and the amount of power to be exchanged through the transmission line. At the same time, the value of the firing angle determines the harmonic levels of voltage and current injected into the DC side of the system. As the value of firing angle increases the magnitude of the harmonic components grows [18]. As explained in section (2.2), the firing angle and commutation angle are the controlling parameres, however, in this investigation the commutation angle was considered to be zero degree for the sake of simplicity. Thirteen different cases of voltage ripples were produced through varying the firing angle from $0^{\circ}$ to $60^{\circ}$ with an interval of $5^{\circ}$ degrees. Figure 5 shows the relation between firing and commutaion angles versus the dominant sixth harmonic (reproduced from [27]).

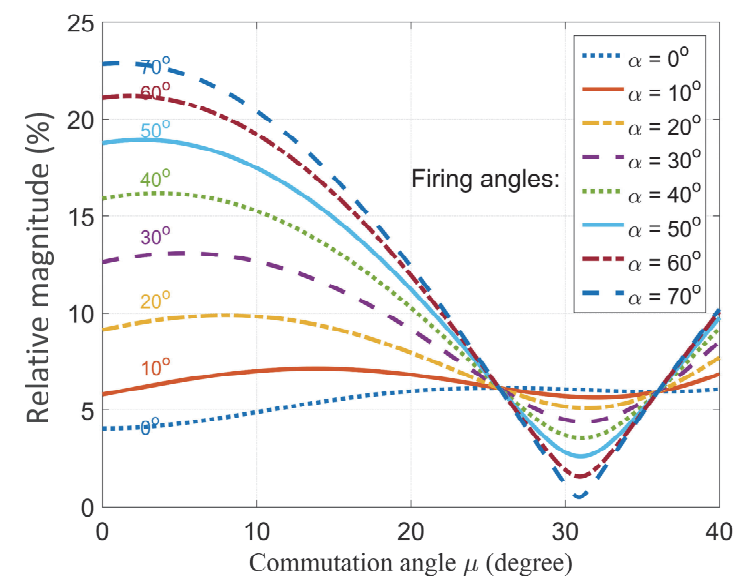

Figure 5. Relative harmonic magnitude ( $6^{\text {th }}$ order) as a function of firing and commutation angles[27].

Figures $6 \mathrm{a}-6 \mathrm{~d}$ depict the applied test voltages along with the detected PD pulses for firing angles of $0^{\circ}, 15^{\circ}, 30^{\circ}$, and $60^{\circ}$ as representatives of the recorded measurements. In figure $6 \mathrm{a}$, the PD pulse occurred near the peak of the rectified waveform. This is the case, according to figure 5, at which the relative magnitude of the dominant 6th harmonic is less than 5 percent for firing and commutation angle of $0^{\circ}$. However, according to $6 \mathrm{~b}-6 \mathrm{~d}, \mathrm{PD}$ pulses tend to occur following the fast transitions in the ripples as well as the peak values of the applied voltages. It is evident that the occurrence of PDs increases as the delay of firing angle increases.

Figure 7 summarises the relationship between number of PD $(N)$, firing delay angle $(\alpha)$ and the inter-time between consecutive PD pulses $(\Delta T)$. It is observable that as the ripple increases- with increasing the firing angle- the number of PD pulses increases and the time interval between consecutive PD pulses reduces as a result of the abrupt changes in the output voltage due to the added higher level of harmonics.

Figure 8 illustrates the maximum magnitudes of the PD pulses against the firing angle that have been recorded under each firing angle $\left(0^{\circ}-60^{\circ}\right)$. It is clear that the magnitudes of PD pulses are declined in higher values of firing delay angles.

This might be explained by the effect of statistical time lag: at voltages with higher magnitude of harmonic components as the PD site reaches its inception voltage, due to higher availability of PD initiating electrons the magnitude of over- 

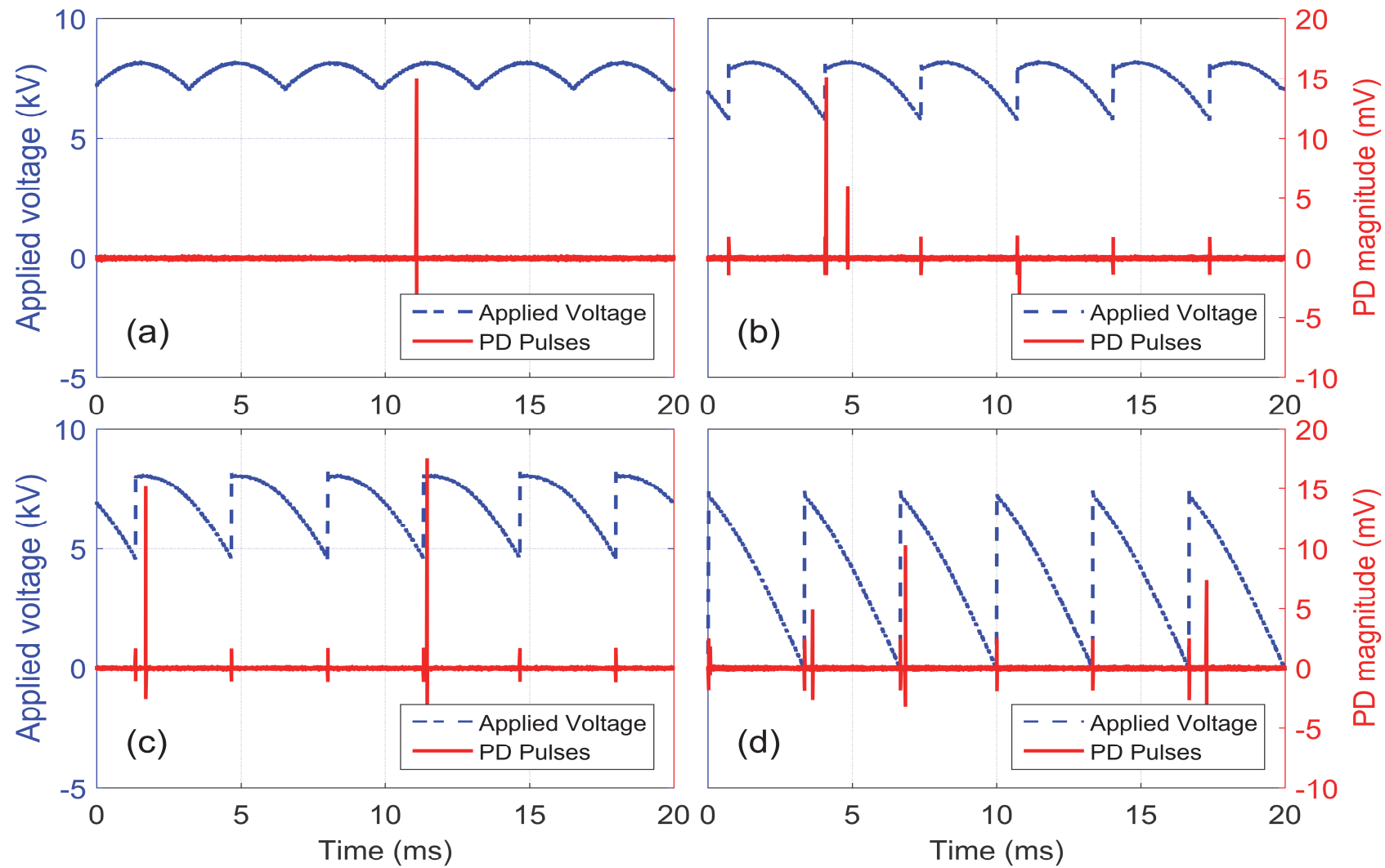

Figure 6. PD pulses under HVDC with firing angle of (a) $0^{\circ}$, (b) $15^{\circ}$, (c) $30^{\circ}$ and (d) $60^{\circ}$.

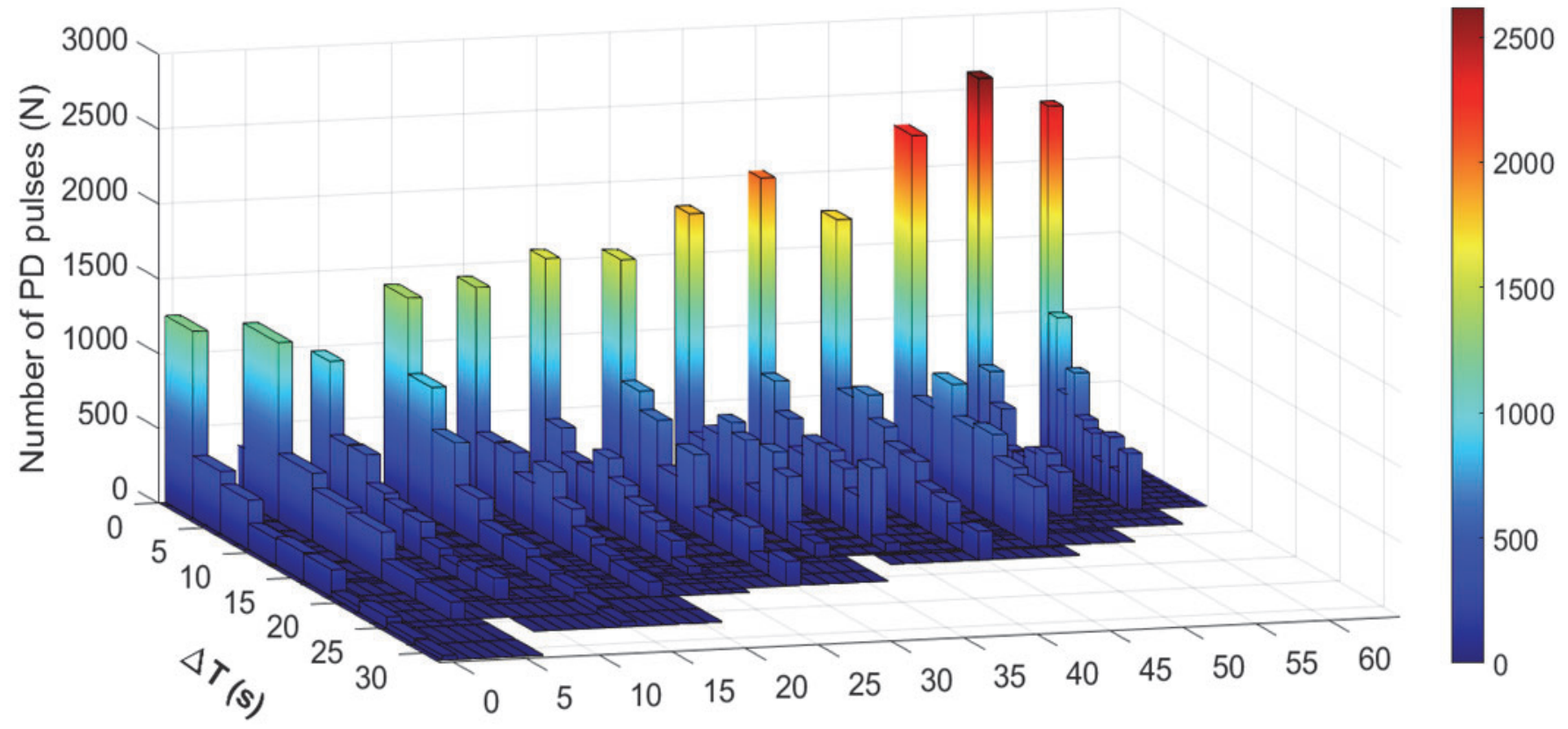

Firing angle $\alpha$ (degree)

Figure 7. Number of PD pulses vs. time difference between consecutive PD pulses vs. firing angle $(\mathrm{N}, \Delta \mathrm{t}, \alpha)$. 


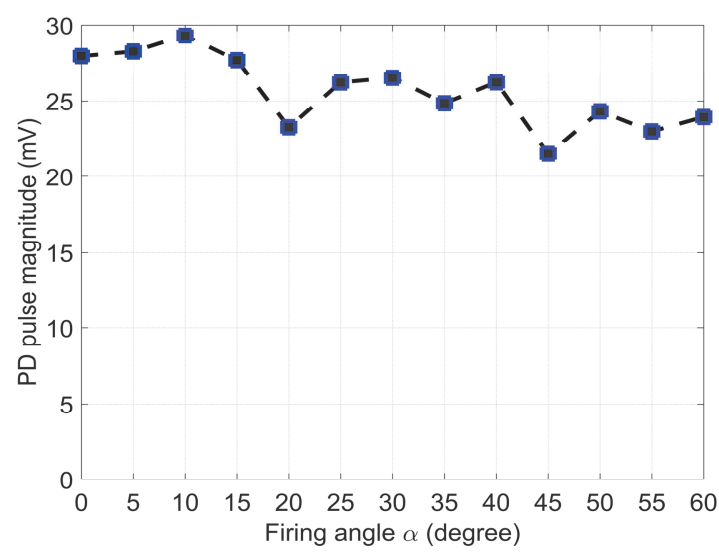

Figure 8. PD magnitude against firing angle.

voltage-drop across the cavity is smaller with respect to the situation of lower harmonics. Hence, PD pulses at DC voltage superimposed with higher harmonic levels have lower magnitude.

\subsection{PD BEHAVIOR UNDER POLARITY REVERSAL}

The LCC schemes are commonly deployed for the purpose of bulk power transmission up to several GW due to availability of highly rated thyristors [28]. Depending on the type of linkage, an interconnection between countries might normally transmit electric power in one direction for a long period, or the redirection of power flow occurs once per day to match peak demand. An HVDC interconnector within a synchronous AC network may experience more than one power redirection depending on the daily conditions. Generally, the polarity changes from negative to positive or vice versa, is performed approximately within one second. The effect of such systematic operational condition of HVDC converters on PD behaviour within the test sample, during the polarity change, is dealt with in this section.

For the purpose of this test, the applied test waveforms were generated to reproduce such scenarios with a bidirectional trapezoidal waveform of $\pm 7.4 \mathrm{kV}$ and the transition between these two states was produced with a ramp of $14.86 \mathrm{kV} / \mathrm{s}$.

Figure 9 and 10 depict the PD pulses that were measured under such transposal conditions from negative to positive and vice versa, respectively. According to the measured data, under both scenarios, mostly PD pulses appear as the applied voltages crosses zero level until reaching their steady state condition. This behavior could be explained as an interaction between the accumulated space charges and the polarity change of the voltage which enhance the net electric field across the defect site within the sample leading to PD occurrence. Figure 11 illustrates the trend of PD pulse repetition rate under both polarity transitions. There is no well-defined trend of PD pulse recurrence, but generally, the number of $\mathrm{PD}$ pulses that occurred during these two transitions drops in the course of time. This reduction in PD occurrences under the polarity change from negative to positive is higher than that of the positive to negative transition.

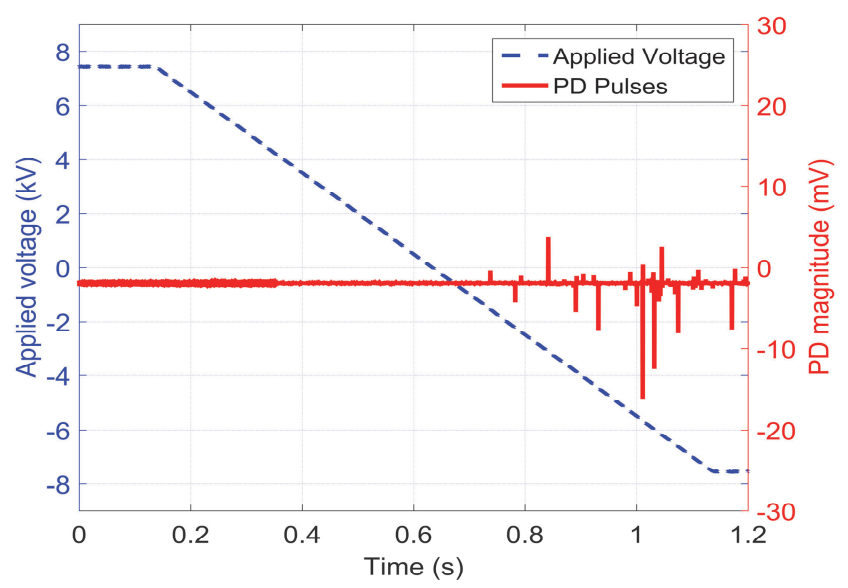

Figure 9. PD during DC polarity transition from negative to positive state.

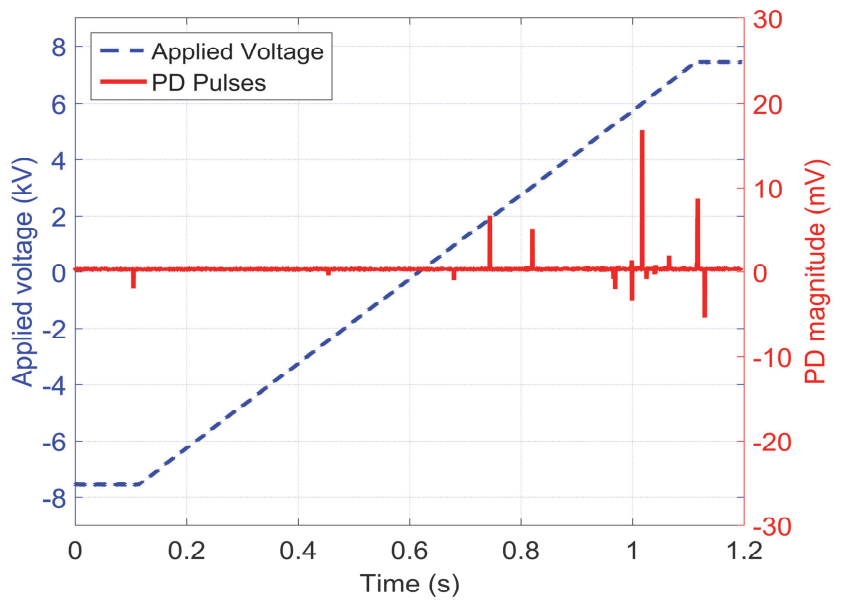

Figure 10. PD during DC polarity transition from negative to positive state.

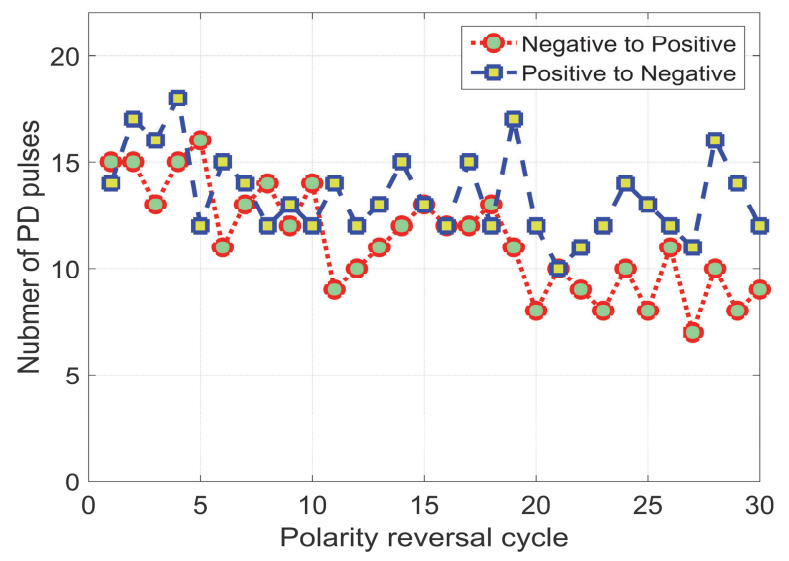

Figure 11. PD trend for both transitions (positive to negative and vice versa).

Figures 12 and 13 illustrate the statistical distributions of maximum PD pulses recorded during polarity reversal transition from positive to negative $(\mathrm{P}-\mathrm{N})$ and negative to positive (N-P), respectively. According to the graphs, the 
magnitudes of the maximum PD pulses under the transition of $\mathrm{N}-\mathrm{P}$ cover a larger range with respect to those that occurred in transition from P-N. In addition, the maximum PD pulses at N-P have higher mean value. However, the distribution of PD pulses at $\mathrm{P}-\mathrm{N}$ has smaller variance.

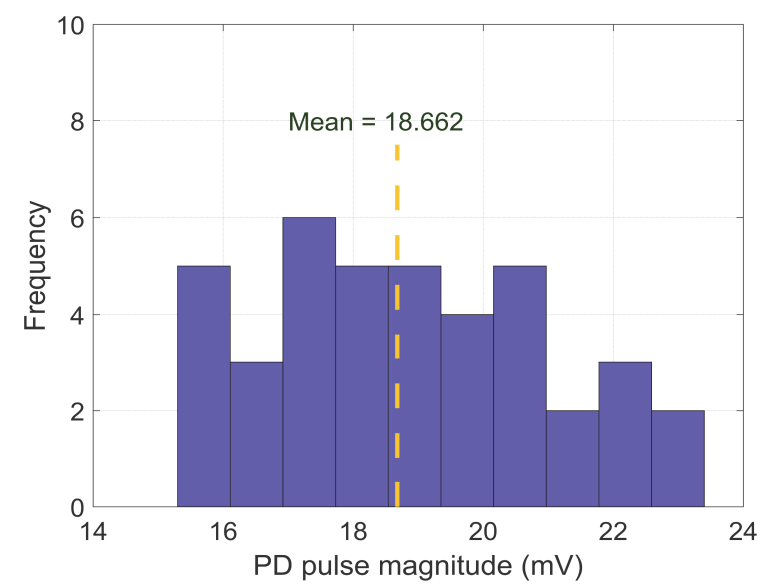

Figure 12. Statistical distribution of maximum PD pulses at positive to negative $(\mathrm{P}-\mathrm{N})$ transitions.

\subsection{PD BEHAVIOR UNDER SWITCHING VOLTAGES}

The transient overvoltages overlay the DC side voltage either in the same polarity or in the opposite [16]. Depending on the type of the superimposition, the imposed Laplacian electric field could either enhance or diminish the Poisson

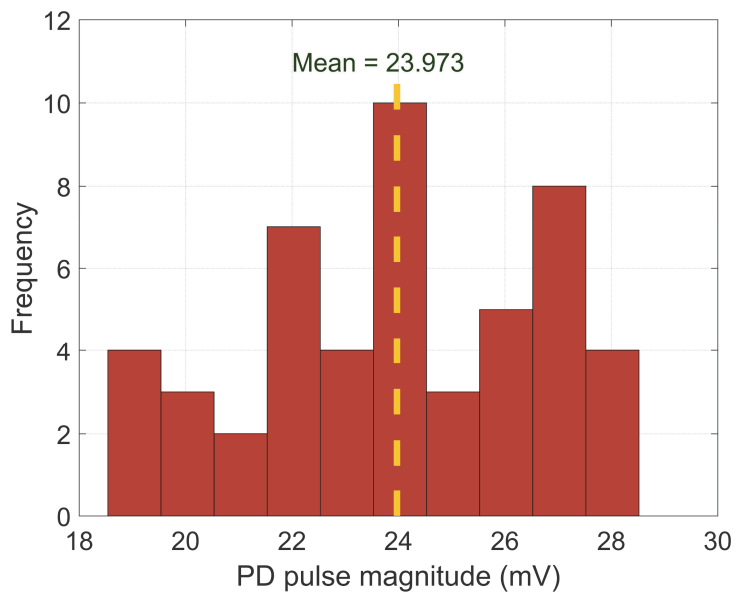

Figure 13. Statistical distribution of maximum PD pulses at negative to positive (N-P) transitions.

field of the already built-up space charges within the insulation [8]. Hence, the intensified resultant electric field could critically affect the cable insulation or even leads to its failure $[16,29]$. In order to study the effects of transient overvoltages on PD behavior within the test sample, DC voltages comprising superimposed transient overvoltages were generated and applied to the sample. The superimposed switching impulses were generated according to IEC 60060-1, where the waveform front time/tail time is $250 / 2500 \mu \mathrm{s}$ [30].

The experiments were conducted under two scenarios: in the first scenario DC voltage was superimposed with the same
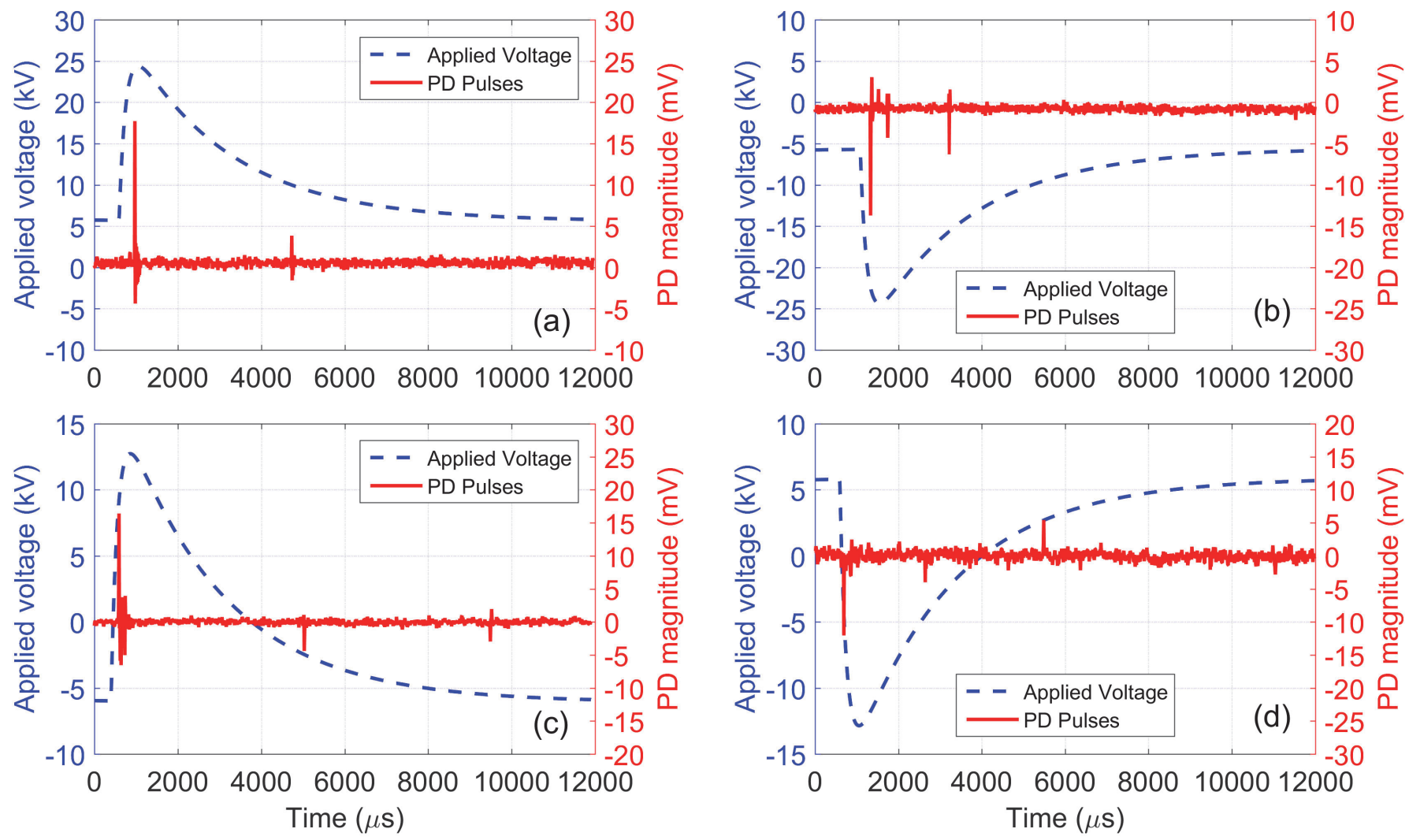

Figure 14. PD pulses at (a) $+\mathrm{DC}+\mathrm{T}$, (b) $-\mathrm{DC}-\mathrm{T}$, (c) $-\mathrm{DC}+\mathrm{T}$, and (d) $+\mathrm{DC}-\mathrm{T}$. 
polarity switching impulse, and in the second scenario, the DC voltage was superimposed with a switching impulse of opposite polarity. Therefore, in the latter the test sample experienced transient polarity reversal. Figures $14 a-14 b$ depict the applied positive and negative test voltages in association with the incident PD pulses under the electric effects of the first group, where the transient overvoltages overly the DC voltages with the same polarity. It is worth noting that the steady state voltage levels, in both cases, were kept below the PD inception voltage of the test sample with the aim of investigating the effects of the overvoltages.

It is evident from the results, under both cases, that PD pulses appear at the rising front of the applied switching overvoltages. These incidents are due to overstressing effects of the switching impulses that exceed the PD threshold level of the defect leading to PD occurrence. Figures $14 \mathrm{c}-14 \mathrm{~d}$ demonstrate the experimental results under the second scenario. Like the first scenario, PD pulses occurred in the rising front of the transient overvoltages, however it is visually evident that the time delay for the occurrence of $\mathrm{PD}$ pulses under the second scenario is rather shorter than that of the first scenario. Therefore, the time delays of both scenarios have been statistically compared. For this purpose, the time delay between PD pulse incidents and the pertinent switching overvoltage were extracted and statistically analyzed.

Figure 15 illustrates the comparison of time lags under both scenarios: negative DC superimposed with positive switching impulse (-DC+T), negative DC superimposed with negative switching impulse (-DC-T), positive DC superimposed with negative switching impulse (+DC-T), and positive DC superimposed with positive switching impulse $(+\mathrm{DC}+\mathrm{T})$. The observed situation might be explained by the influence of the accumulated space charges. The appearance of PD pulses with shorter delays after the incident of switching impulse, under the case of DC superimposed with opposite polarity, indicates the build-up of hetro-charges within the sample, where the Poisson field from the accumulated space charges enhance the Laplacian field from the externally applied test voltages (as the polarity changing occurs) and exceeds the PD threshold resulting to PD occurrence in a shorter time with respect to the case of DC superimposition with similar polarity of transient overvoltages.

\section{DISCUSION}

Insulating materials behave differently when exposed to different types of electric fields due to interactions between the driving voltages and the electrical properties of the dielectrics.

Thus, the embedded non-homogeneities (defects) within the insulation react accordingly. Under the influence of alternating features of an AC voltage, dielectrics behave capacitively and, furthermore, under such bipolar fields space charges rarely build up. Therefore, at AC fields the emanating PDs within an insulation system take on a repetitive activity creating specific patterns depending on their origins.

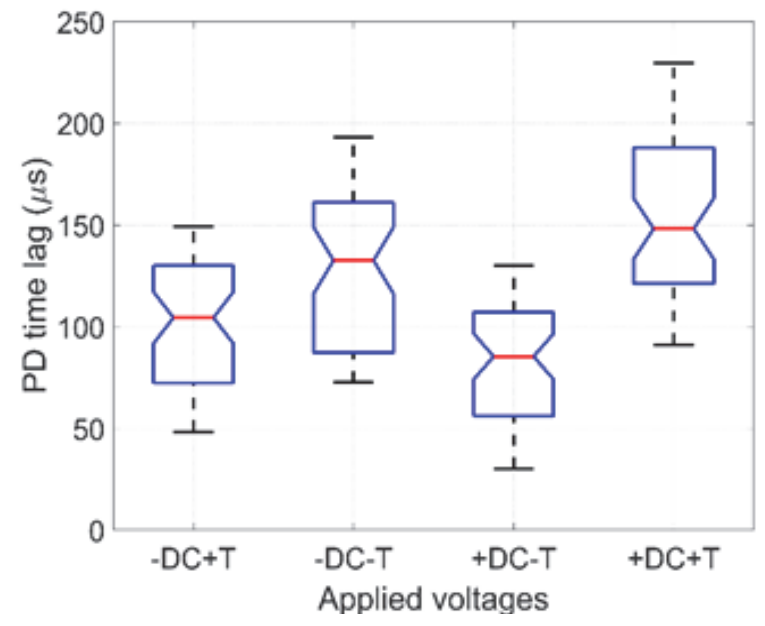

Figure 15. Time lag of PD occurrence under the four different scenarios of transient switching overvoltages.

However, such a behavior is absent under the steady state DC electric fields. DC PDs possess an infrequent occurrence due to the effect of non-varying DC fields. The reason underlying this is the behavior of the dielectric materials when subjected to steady state DC voltages. Under such conditions, the electric field distribution within the dielectric is governed by its conductivity $(\sigma)$, where it is mainly a function of the material composition and the temperature.

Nevertheless, the voltages that HVDC cables experience in the real scenarios are not a purely smooth DC voltage, but contain ripples and are exposed to transient overvoltages of many types as discussed. In such situations, the insulation experiences sudden field changes and behaves pseudocapacitively. The rising front of overvoltages are comparable to a quarter of an $\mathrm{AC}$ cycle which influences the state of already accumulated space charge and redistributes them leading to increased probability of PD occurrence at the defect point. Accordingly, under the influence of voltage ripples PD activity within the sample shows an observable increase in repetition, which can be explained as the effect of transient voltage that redistributes the net electric field within the sample.

The experimental results of PD measurements under operational polarity reversal - positive to negative transition and vice versa - show that PD pulses appear at the zero crossing of the applied voltage and their activity lasts until the voltage settles in its new steady state. Analogously, similar behavior can be observed under transient polarity reversal. Mainly, the PD pulses occurred at the rising front of the waveforms. Such behavior of PDs in the test sample could be explained by the interaction between the accumulated space charge and the fast-changing voltages which results in a locally enhanced electric field leading to PD occurrence despite the fact that the steady state level of the underlying DC voltage was kept below the PD threshold of the sample.

\section{CONCLUSION}

Appropriate levels of terminal voltage of LCC converter, polarity reversal and switching transient under laboratory 
conditions were generated and applied to a well-defined polymeric test sample and the PD behavior under such conditions were measured and analyzed. Under the effect of voltage ripples an observable relation was found between the PD pulses and the ripples, particularly the PD incidents correlated to a lesser or greater degree with superimposed peak voltage: as the firing angle increases $\mathrm{PD}$ pulse repetition augments given in the relevant $(\mathrm{N}, \Delta \mathrm{T}, \alpha)$ pattern. During polarity reversal, the phenomenon of space charge accumulation reflects notably in PD behaviour. As the transition between the two polarities occurs, PD is present despite the steady state DC value being lower than the PD inception level. PD measurement under the effect of superimposed switching transients shows a correlation between PD occurrence and the transient incidents indicating the influence of fast rising front of the overvoltages on PD occurrence. It is anticipated that the outcomes of this study will assist in the understanding of PD behaviour under operating conditions and anomalies that could be present in HVDC systems affecting interconnecting cable systems. Considering the effects of such phenomena on PD behaviour could assist network operators in insulation diagnostics and hence asset management.

\section{REFERENCES}

[1] A. William, Electrical Power Cable Engineering, 2nd ed., Marcel Dekker Inc., New York, 1999.

[2] A. Gustafsson, M. Saltzer, A. Farkas, H. Ghorbani, T. Quist, and M. Jeroense, "The new $525 \mathrm{kV}$ extruded HVDC cable system," ABB Grid Systems, Technical Paper, 2014.

[3] D. Fabiani and G. Montanari, "The effect of voltage distortion on ageing acceleration of insulation systems under partial discharge activity," IEEE Trans. Dielectr. Electr. Insul., Vol. 17, pp. 24-33, 2001.

[4] M. Florkowski and B. Florkowska, "Distortion of Partial-Discharge Images Caused by High-Voltage Harmonics," IEE Proc. Generation, Transmission and Distribution, Vol. 153, pp. 171-180, 2006.

[5] N. Hayakawa, M. Morikawa and H. Okubo "Partial Discharge Inception and Propagation Characteristics of Magnet Wire for Inverter-fed Motor under Surge Voltage Application," IEEE Trans. Dielectr. Electr. Insul., Vol. 14, pp. 39-45, Feb. 2007.

[6] IEC60270, High Voltage Test Techniques - Partial Discharge Measurements. British Standards Institution, 1st ed., 2000.

[7] IEC62478, High Voltage Test Techniques- Measurements of Partial Discharge by Electromagnetic and Acoustic Methods. British Standards Institution, 1st draft, 2012.

[8] P. Morshuis and J. Smit, "Partial discharges at dc voltage: their mechanism, detection and analysis," IEEE Trans. Dielectr. Electr. Insul., Vol. 12, pp. 328-340, 2005.

[9] A. Cavallini, G. Montanari, Marco Tozzi, and Xiaolin Chen, "Diagnostic of hvdc systems using partial discharges," IEEE Trans. Dielectr. Electr. Insul., Vol. 18, No. 1, pp. 275-283, 2011.

[10] G. Mazzanti, "Reliability evaluation of insulation subjected to harmonic voltages within the limits set by international standards," IEEE Trans. Dielectr. Electr. Insul., Vol. 12, pp. 2037-2046, 2014.

[11] P. Olsen, F. Mauseth, and E. Ildstad, "The Effect of DC Superimposed AC Voltage on Partial Discharges in Dielectric Bounded Cavities," Int'l. Conf. High Voltage Eng. Application (ICHVE), pp. 1-4, 2014.

[12] M. A. Fard, A. J. Reid and D. M. Hepburn, "Finite element model of HVDC converter harmonic effects on partial discharge," IEEE Int'1. Conf. Dielectrics (ICD), pp. 716-719, 2016

[13] T. Jiang, A. Cavallini, G. Montanari, and J. Li, "The Role of HVDC Voltage Waveforms on Partial Discharge Activity in Paper/Oil Insulation," IEEE Conf. Electr. Insul. Dielectr. Phenomena (CEIDP), pp. 424-427, 2012.

[14] M. A. Fard, A. J. Reid, D. M. Hepburn and H. Gallagher "Influence of voltage harmonic phenomena on partial discharge behavior at HVDC," IEEE Int'l. Conf. Dielectr. (ICD), pp. 548-551, 2016.
[15] D. Fabiani, G. C Montanari, C. Laurent, G. Teyssedre, P. H. F. Morshuis, R. Bodega, L. A. Dissado, A. Campus and U. H. Nilsson, " Polymeric HVDC Cable Design and Space Charge Accumulation. Part 1: Insulation/Semicon Interface," IEEE Electr. Insul. Mag., Vol. 23, No. 6, pp. 11-19, 2007.

[16] G. Mazzanti and M. Marzinotto, Extruded Cables for High-Voltage Direct-Current Transmission: Advances in Research and Development, 1st ed., Wiley IEEE Press, New Jersey, USA, 2013.

[17] M. Salah Khalil, "International research and development trends and problems of hvdc cables with polymeric insulation," IEEE Electr. Insul. Mag., Vol. 13, No. 6, pp. 35-47, 2002.

[18] J. Arrillaga, High Voltage Direct Current Transmission, 1st ed., Institute of Electrical Engineering, London, 1998.

[19] W. McDermid and T. Black, "Experience with Preventing External Flashovers in HVDC Converter Stations," IEEE Int'l. Sympos. Electr. Insul. (ISEI), Vancouver, Canada, pp. 81-84, 2008.

[20] IEC 60060-1, High-Voltage Test Techniques - Part 1: General Definitions and Test Requirements, 2010.

[21] M. K. Bucher and C. M. Franck, "Comparison of Fault Currents in Multiterminal HVDC Grids with Different Grounding Schemes," IEEE PES General Meeting, Conf. Exposition pp. 1-5, National Harbor, USA, 2014.

[22] E. W. Kimbark. "Transient overvoltages caused by monopolar ground fault on bipolar dc line: theory and simulation," IEEE Trans. Power App. Syst., vol. PAS-89, no. 4, pp. 584-592, April 1970.

[23] J. Candelaria and J.-D. Park, "VSC-HVDC System Protection: A review of Current Methods," IEEE Power Systems Conf. Exposition (PSCE), pp. 1-7, Phoenix, USA, 2011

[24] Z. Sun, X. Zhao, J. Li and Y. Li, "Experiment Investigation of Partial Discharges under Impulse Voltage," IEEE 9th Int'1. Conf. Properties and Applications of Dielectr. Materials, Harbin, China, pp. 525-529, 2009.

[25] A. Cavallini; D. Fabiani, G.C. Montanari, "Evaluation of Motor Winding Insulation Performance Under Pulse Waveforms Through Electrical Measurements," Int'l. Wire Cable Conf., Guilford, UK, pp. 293-299, 2007.

[26] J. Fothergill, "The Coming of Age of HVDC Extruded Power Cables," IEEE Electr. Insul. Conf. (EIC), pp. 124-137, 2014.

[27] J. Arrillaga and N. R. Watson, Power System Harmonics, 2nd ed., Wiley West Sussex, UK, 2003.

[28] R. Majumder, C. Bartzsch, P. Kohnstam, E. Fullerton, A. Finn, and W. Galli. "Magic bus: high-voltage dc on the new power transmission highway," IEEE Power and Energy Mag., Vol. 10, No. 6, pp. 39-49, 2012.

[29] G.C. Montanari and G. Mazzanti, "Recent developments in insulation life modeling," Revue Electri. Electron, Vol. 3, pp. 66-72, 1998.

[30] IEC 60060-1, High-Voltage Test Techniques - Part 1: General Definitions and Test Requirements, 2010.

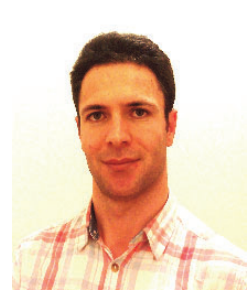

M. Azizian Fard (GSM'14) received the B.Sc. degree from Shiraz University, Shiraz, Iran in 2007, the M.Sc. degree from K. N. Toosi University of Technology, Tehran, Iran in 2010 and now he is pursuing his $\mathrm{PhD}$ at Glasgow Caledonian University, Glasgow, UK. He is a student member of CIGRÉ CIGRÉ-UK NGN, IET, IEEE DEIS, IEEE IAS and a volunteering member of IET SW committee in Glasgow. He worked as a design and technical engineer in oil and gas industry and protection equipment manufacturing company, respectively, before starting his $\mathrm{PhD}$. His interests include condition monitoring, partial discharge, insulation diagnostics and power electronics.

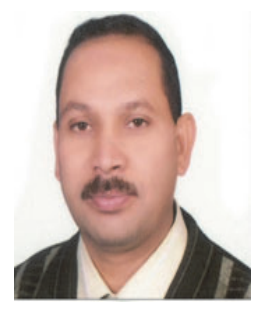

Mohamed E. A. Farrag (M'99) was born in Assiut, Egypt, in 1967. He received the B.Sc. and M.Sc. degrees in electronics engineering from Menoufia University, Menoufia, Egypt, in 1990 and 1996, respectively, and the Ph.D. degree from Northumbria University, Newcastle, U.K., in 2002. He was a Lecturer of Electrical Engineering, Faculty of Industrial Education, Helwan University, Cairo, Egypt, between 2003 and 2007. He joined Northumbria University as a Visiting Lecturer in 2008 and then joined the Institute of Energy and Sustainable Development, De Montfort University, Leicester, U.K., as a Research Fellow. Currently, he is Senior Lecturer with the Department of Engineering, School of Engineering and Built Environment, Glasgow Caledonian University, Glasgow, U.K., where he is engaged in research on power system control and operation, renewable energy integration and energy storage systems. 


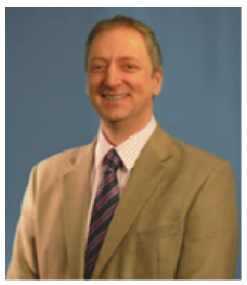

Scott McMeekin is a Professor in the School of Engineering and Built Environment at Glasgow Caledonian University. He received a $\mathrm{BSc}$ degree from The University of Strathclyde in 1985 and the MSc and $\mathrm{PhD}$ degrees from The University of Glasgow in 1986 and 1989 respectively. Prior to joining Glasgow Caledonian University, he was the Process Development manager at Alcatel Optronics Ltd (formerly Kymata Ltd) where he was responsible for the development and qualification of novel optical components for advanced optical telecommunication systems. He has previously worked at the Universities of Cardiff and Glasgow. His current research interests include the development of Instrumentation and Sensor Systems with a specific interest in the condition monitoring of energy assets and the development of photonic bio-sensors. He has published over 110 journal and conferences articles and is co-inventor on 6 patents.

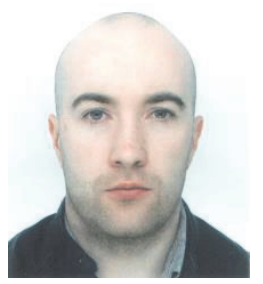

Alistair J. Reid (M'11-SM'15) graduated from the University of Strathclyde, UK, in 2004 with a B.Eng. (Hons) degree in Electrical and Mechanical Engineering and received the Ph.D. degree in 2007 for research on partial discharge monitoring. Subsequently, he has worked as a Post-Docroral Research at the University of Strathclyde, a Research Fellow at Glasgow Caledonian University and a Visiting Research Associate at California Institute of Technology. He is presently an assistant professor at Cardiff University. His research interests include diagnostic monitoring techniques and systems, partial discharge, sensor design, embedded systems and energy harvesting. Alistair is a Senior Member of the IEEE and a committee member of the Universities High Voltage Network (UHVnet) in the UK. 